University for Business and Technology in Kosovo

UBT Knowledge Center

UBT International Conference

2014 UBT International Conference

Nov 8th, 2:15 PM - 2:30 PM

\title{
It's all about living sustainable: (A research of communicating sustainable way of living to the public)
}

\author{
Gafur Asani \\ University of Liechtenstein, gafur.asani@uni.li \\ Dietrich Schwarz \\ University of Liechtenstein, dietrich.schwarz@uni.li \\ Manuel Sebastian Du
}

Follow this and additional works at: https://knowledgecenter.ubt-uni.net/conference

Part of the Architecture Commons

\section{Recommended Citation}

Asani, Gafur; Schwarz, Dietrich; and Du, Manuel Sebastian, "It's all about living sustainable: (A research of communicating sustainable way of living to the public)" (2014). UBT International Conference. 10. https://knowledgecenter.ubt-uni.net/conference/2014/all-events/10

This Event is brought to you for free and open access by the Publication and Journals at UBT Knowledge Center. It has been accepted for inclusion in UBT International Conference by an authorized administrator of UBT Knowledge Center. For more information, please contact knowledge.center@ubt-uni.net. 


\title{
It's all about living sustainable: (A research of communicating sustainable way of living to the public)
}

\author{
Gafur Asani ${ }^{1}$, Dietrich Schwarz ${ }^{2}$, Manuel Sebastian $\mathrm{Du}^{3}$ \\ 123 Department of Sustainable Design, University of Liechtenstein \\ gafur.asani@uni.li, dietrich.schwarz@uni.li
}

\begin{abstract}
Living sustainable, a vision that I developed at the Design Studio Schwarz, University of Liechtenstein. Living sustainable raises questions about living in balance with our natural resources. We are living on costs of next generations, so we are responsible to make the changes with architectural interventions in our society for our society. Based on „World Energy Council“" report of 2011, our planet will have 2.2 billion inhabitants more on 2050, reaching 9.2 billion, by challenging a huge demand on mobility, food, goods and building as well. In order to having a bigger impact and a better control over growing up-mentioned demands, professionals have to take the first steps on treating these issues not only in universities, schools or other institutions, but to make aware also the common people, considering as main starting point where the „problems“ or demands start from. Better communication of sustainable architecture to the common people could help to understand that humans are living in a planet with limited bio capacity and their demands will have to be reduced and controlled by professionals, which helps living and growing future settlements in balance with nature and helps reducing their ecological footprint, as one of the most important aspect of sustainability.
\end{abstract}

Keywords: Sustainability, Density, Environmental Impact, Public, Footprint.

\section{Introduction}

The One Planet Society, a vision towards sustainable architecture, with tendency on bringing new sustainable ways of living for communities and planning their growth in balance with natural resources. The world's population is growing dramatically fast, but the living area in the planet is the same as before, so the only realistic feedback is finding new sustainable ways of living with architectural interventions, which could help on keeping the life quality in balance with population growth and incapacity. Today sustainability is a topic which is spoken almost everywhere in the institutes, schools, training centers, etc. and the idea is about spreading it also to common people, in order to start with changes in society as soon as possible. This research is about simplifying and communicating to the public new ways of sustainable living and proving life in optimal space. Living in sustainable buildings with an average of $20 \mathrm{~m}^{2} /$ person doesn't really mean a bed life quality, like living in a cage and eating only potatoes, but actually it means living in spaces not bigger that we need and consuming goods in a better organized way in order to reduce mobility and have lower environmental impact. Common people shouldn' $t$ be frightened when they hear about sustainable living, because it's on their favor, it's on their children favor and they have to be aware that we have only one planet where we could build and live and we are the owners, so we have to take care of it by trying to reduce their ecological footprint by rational living in optimal spaces.

Nowadays there are a lot of studies and experiments made about reducing ecological footprint by building, mobility, food production and so on, but these are not well communicated to the public jet. It is necessary to make the common people aware and make them understand which are sustainable concepts and what is living in sustainable way, because they could have a huge impact on supporting such concepts even implementing them, which is indirectly a step forward to reducing their ecological footprint. Integrating common people in this process could impact the environment, because they would 
also think of this issue in global level. So, for finding better ways to communicating sustainable concepts to the public we develop a research about the question: How can we communicate sustainable architecture to the public, in order to reduce environmental impact?

The working methods about developing this question will be questionnaires, interviews, discussions, exhibition and literature. In order to easily communicate sustainable concepts this book is structured in three parts: general researches about communicating sustainability, examples of sustainable ways of living and discussion of the results and methods of doing it. The first part will be provided with general understanding of sustainability and treatment of communicating sustainability to the public, at the second part there are projects about sustainable way of living which we developed in Design Studio Schwarz, and in the third part there is structured the discussion of the results shown from literature, discussions, interviews, questionnaires and exhibition. We simplify and clarify the communication about sustainability to the public/reader and prove that sustainable way of living for sure will be one of the main topics of humanity over next century.

\section{Sustainability introduction}

The term sustainability is mainly used to express long lasting solutions for humanity, in fields of science, society, economy, environment, space, etc. The term „,being sustainable“ means to being rational in using natural resources in general and making them easily maintainable during the time of their usage or existence. The word sustainability was first found to have been mentioned in literature of early 18 th century from a German nobleman Hans Carl von Carlowitz.

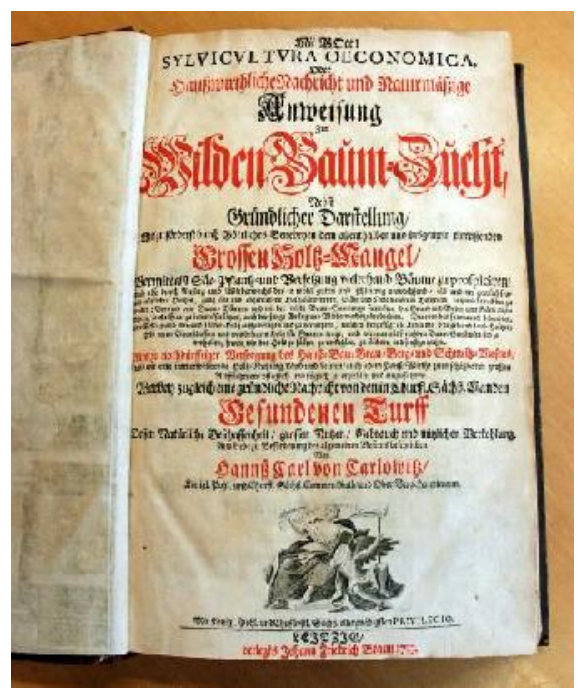

Fig.1. Sylviculturaoeconomica: Titelseite. Photography: FVA/Weidner

He mentioned it in German Language „Nachhaltigkeit“ when he explained the sustainable way of using wood for timber productions. He explained how could a sustainable solution for the forest could be, by cutting the wood in balance with the capacity of forest to grow them back within a certain time, so with this balance they will be able to use the wood in a longer life span without destroying the nature and also without effecting up coming generations. So, sustainability was about planting new trees in order that next generations could use them as well, because environmental damage was raised in that time by clearing to much woodland, which is also a problem nowadays too in some non-developed countries. From that time on, sustainability as a term and also as approach started spreading around worldwide, especially last century in different fields such as environmental aspects, social and economic ones. In 1992 there were organized an international environmental conference in Rio de Janeiro, Brazil, where 
was created „Agenda 21“, as a counteract an advancing degradation of the situation of the people on the globe. And it needed many years of intensive work before different countries agreed on it. Now, sustainability is widely spoken in different summits, conferences, etc., in order to proceed with new strategies about sustainable developments for the future.

\subsection{Three - pillar model of sustainability}

The three-dimensional model proceeds on the assumption that sustainability can be achieved by realization of environmental, social and economic aspects.

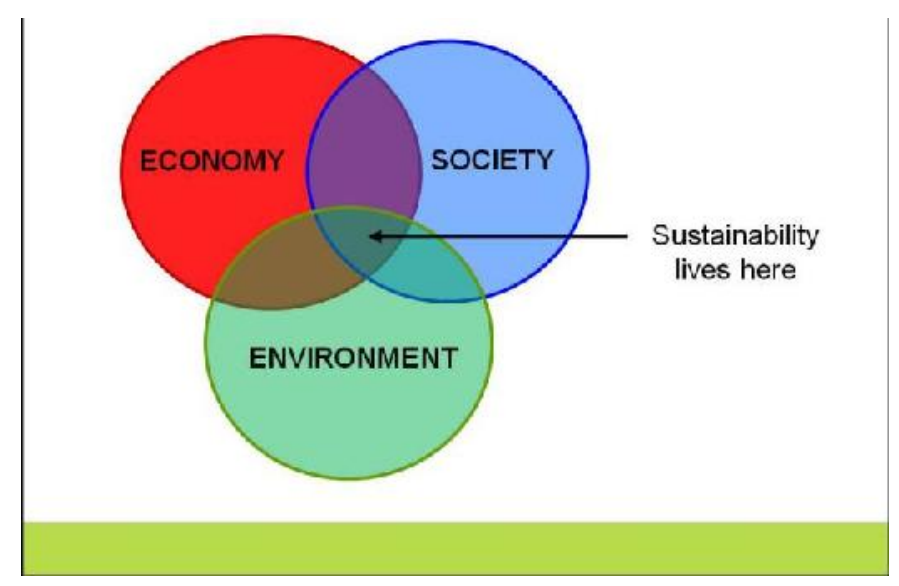

There should be a social community with an efficient economy and working tog Fig

Fig. 2. Three pillars of sustainability

There should be a social community with an efficient economy and working togetheı aıu пuксu to the environment to create a sustainable development in a three based sustainable aspects. These aspects should be equal and homogeneous to each other to achieve their common aim which is securing and improvement of economic, ecologic and social effectiveness. We can differentiate sustainability between ,weak“ and „strong“ within their three pillars model. With weak sustainability is meant when you assume that it doesn't matter in which dimension capital is conserved or created. In this case would be acceptable if natural resources run out when it is confronted with an big amount of people. Strong sustainability means that natural capital is not or just very limited replaceable to people. It is comparable to a crash barrier model. The ecological parameters represent a progress corridor which limits have to be observed and to ensure a stable conditions for life.

\subsection{Ecological footprint calculation}

Ecological footprint provides a method of calculating the consumptions of natural resources of every human being. This calculation makes possible to know better about peoples impact to the nature, in basis of individual calculation of their ecological footprint. Actually, it shows people's demand toward planet's ecosystem. This includes not only living space, streets, productive land, but also forests and sea including the food which is produced from them, fossil oil, petroleum and kerosene are calculated too, in terms of mobility. The unit which is used to measure this demand is the global hectare (gha), which presents the average productivity of all the biologically productive land and sea in the world for the given period. These days the world consumes five times more than the environment can produce it. But 
this consumption is unequally distributed by splitting this consumption between industrialized countries and non-industrialized ones. „USA have the biggest consumption in the planet, their consume is 9 hectares per person, in relation to 4.6 ha in the EU. (Petri, F., 2006). The fact that the population on earth will still continue to rise is an amplifying problem. It is prophesied that there will be over 10 billion of people on this planet by 2050 , and it is hard to believe that the earth could absorb this.

There are five main elements which can contribute to ecological footprint, such as; foot, goods, services, shelter and mobility. Food, is an obvious factor of impacting our footprint, because the demand is always growing by growth of populations, and for this food demand we need productive land. Goods, together with food covers the whole people's demand of day life. Here the two defining factors are what is consumed and especially to what extent. Services, are also important elements in terms of ecofootprint, and it's directly connected with roads, infrastructures, public services. Shelter, is also an important factor, especially nowadays where the complexity of the dwellings is getting higher, which means the demands for different resources arises. Mobility, is a key factor nowadays, in a time of growing globalization. The demand is always growing and the ecological impact is getting higher and higher.

\subsection{Aims of sustainability}

The main idea of sustainability is efficiency on cultivating natural resources and efficiency on using them in our daily life. The forests as a natural resources are also important for the extraction of the wood which is used in many fields. The word sustainability starts from the forests, because of its importance on climate of the world because of the photosynthesis which is made from the trees. That means plants can transform carbon dioxide $\left(\mathrm{CO}_{2}\right)$ into oxygen. This attribute makes the forests so significant, because of $\mathrm{CO}_{2}$ mainly influences the greenhouse effect and every living creature. The forests also represent a valuable environment for many kinds of animals and plants, which means by sustainability we take care for biodiversity of our planet. That's why we have to use these resources as efficient as we can. Another aim is water, especially the industrialized countries are wasting water across the world. Not just drinking water, which is getting low in many countries of the world but also the water for the normal household. Half of the world populations are not adequate provided with water and the main problems are followed by diseases from contaminated drinking water. Waste as another important aim for sustainability, needs to be well organized in the future in order to be reused the wasted materials. There are different kinds of waste that we are producing as human beings in the planet. Compliant with Terry (1997) the waste from mining or oil drilling is definite the outstanding source. Some kind of waste can be recycled and reused, but some of them cannot be used anymore, these are for example toxic wastes which are hazardous to the environment. There are different ways to deal with waste, but there are problems with time, money and effort to convert them.

\subsection{0-watt society}

Sustainability is a matter that concerns to everyone: if we continue with consumption of natural resources like we are consuming today, we or next generations will face a drastic climate change in our planet, that's why we have to take actions as fast as possible in all levels, in order to improve sustainable performances of humanity.

Two thousand watts is the average rate of the world's energy consumption, and also reflects the society of 1960's when the consumption was the same. This vision first came on 1998 from Swiss Federal Institute of Technology in Zürich, and their intention is to reducing overall energy consumption up to 2000 watts or 48 kilowatt-hours per day until 2050 without effecting life quality, which researches say it could be possible. This initiative is not only about individual consumers, but it's also about bigger society with different population. In the other countries less industrialized we have different energy usage, such as; western Europe 6,000 watts, USA 12,000 watts, China 1,500 watts, South Africa 500 watts, and Bangladesh only with 300 watts, Switzerland currently is using 6000 watts. In order to fulfilling the aim of 2000-watt society there are a lot of measurements needed to be taken, such as; reinvestments in capita assets, in order to bringing it up to low energy building standards, efficiency of 
the road transport and air transport, the use of material, heating systems, the use of renewable energy, etc.

Renewable energies should be more used nowadays and further developed in the future because they do not destroy the environment and they will serve as helpful solutions for the next generations. There are other helping solutions of renewable energies, and the best known solutions are wind, water, solar and geothermal energies. Wind energy by converting kinetic energy of moving air masses into electricity by a generation. Water power, as a power of moving or falling water can

actuate turbines to create electricity. The big advantage of water energy is that it is quite easy to store the energy so that you can use it in near future. Geothermal energy is about using the underground heat. This heat could be managed by a big power plant, or by private residential buildings. Solar energy is a renewable energy because it gets use of the sun to produce electricity and hot water. Photovoltaic can transform rays into electricity. These are the main energy resources which will be fully used in the future in order to stabilize the demand of humanity in the planet.

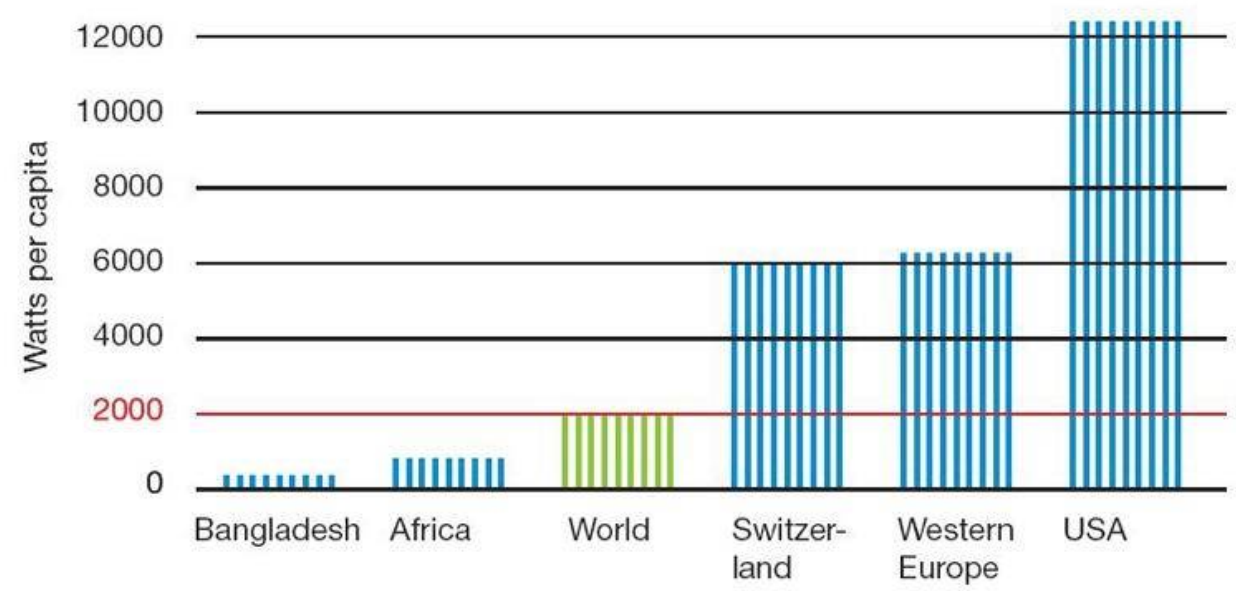

Fig. 3. Global energy consumption, source: www.stadt-zürich.ch

\subsection{Global mobility}

Based on population growth on our planet, it's quiet obvious that their demand for mobility is growing too. In next four decades the global transport will face unprecedented challenges related to demographics, urbanization, pressure to minimize and dislocate emissions outside urban areas, and also in growth of fuel demand. In order to positively meet these changes, it's necessary to have constructive dialogue with national policy makers, manufactures and consumers. With finding new alternative ways of producing energy, by promoting and communicating it, we can have a sustainable transport for current and future generations.

In 2010 global mobility sector consumed about 2.200 million tons of oil, constituting about $19 \%$ of global energy supplies; it is about $96 \%$ from oil, the rest from natural gas, biofuels and electricity. More than $60 \%$ of the consumed oil globally (around 51 million barrels/day) goes to mobility.

As figure shows road transport has an amount of $76 \%$ of the transport energy consumption. The lightduty vehicles including trucks, minibuses, light commercial vehicles accounted $52 \%$, while heavy-duty accounted for $17 \%$. The remaining share of road transport was covered by full-sized buses $4 \%$, twothree wheelers $3 \%$. Air and marine accounted about $10 \%$ of total energy consumption, while the railway only 3\%. WEF, Repowering transport, 2001.

„Despite steady growth in global energy use, various regions and countries show not only different energy-user growth rates per transport mode, but also in different patterns in terms of both energy use 
per capita and type of fuel used."WEC, 2011. In terms of differences in energy use per capita and types of fuel used, different countries apply different kind of traveling system. For example, undeveloped countries use cars, light trucks, minibuses, etc. much more than developed countries, while developed countries use more public transport and for long distances air transport.

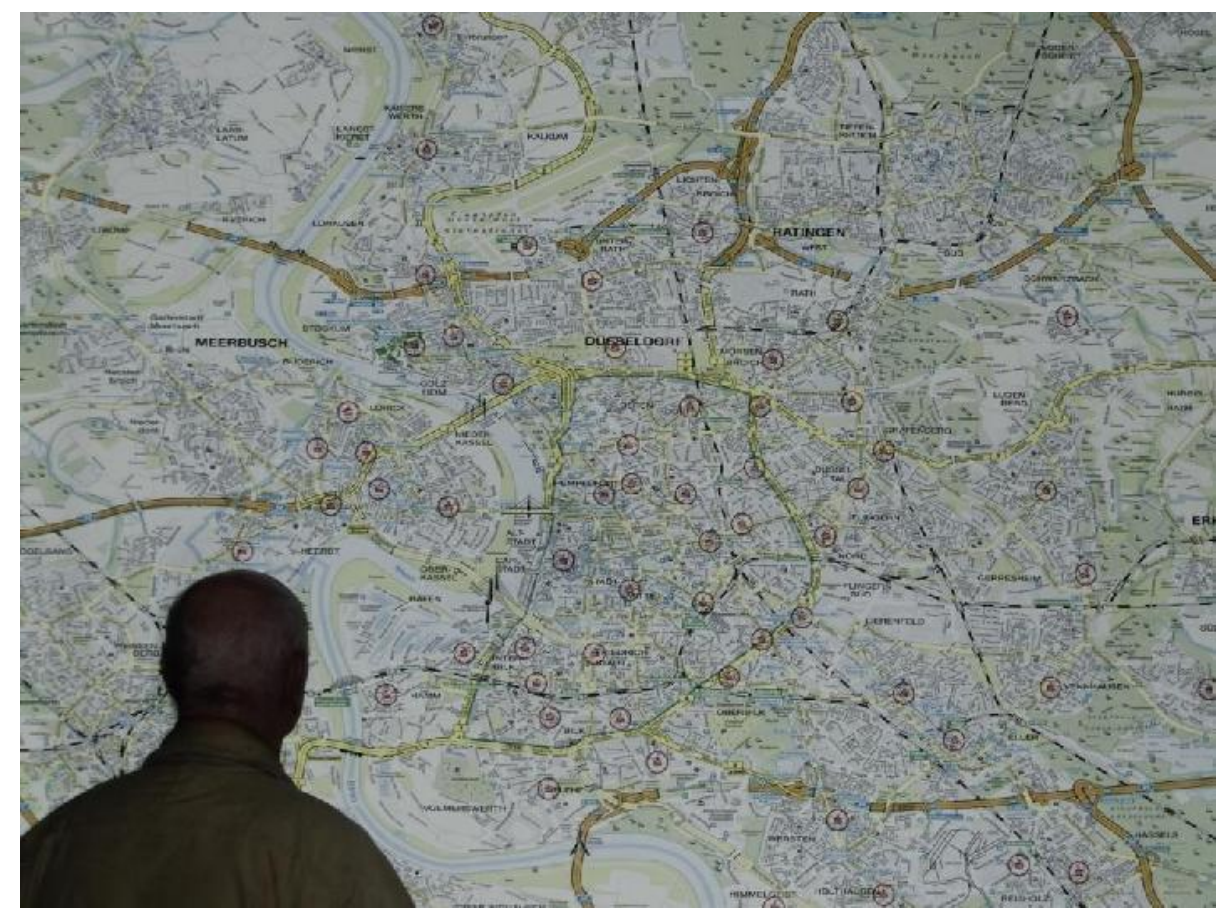

Fig. 4. Man Facing Mobility, Photography: G.Asani

\subsection{Global food consumption}

In last 20 years, global demand for food is increasing obviously, along with population growth in our planet. Food production is increasing steady, but also prices too. There are different organizations and programs working in global level to help food production in poor countries in order to use local resources and stop food transport.

Based on ecological footprint calculation, food consumption today is a huge issue with environmental impact. Mobility has made possible to transport food from different countries all over the world, but environmental impact is not solved yet, unless we use local food and local resources. Food issue make us think about creating urban settlements in relation with productive land around it, this helps to minimizing food transport and reducing footprint. There are also different theories and designing methods about developing self-sufficient urban settlements, this means that urban settlements should have a limited number of inhabitants based on productive land that is around it, and there should be also a limited distance from productive land to urban settlement in order to keep the balance of growth and existing nature.

\section{Communicating sustainability}

The idea of communicating sustainable way of living to the public, comes from the need of improving life quality in futuristic dense cities, to improve social-behavior between communities who are living next to each other, from the need to saving the productive land and building land and to reduce mobility, which is considered as a major issue in terms of global warming. The awareness of the people about 
sustainability would lead to taking the advantage of residual spaces to build and bring the density into the cities, which is possibility to improve incapacity of a city, to reduce the mobility for transporting goods and it also helps to develop a better social life in the future cities, by 2050 megacities are expected to increase from today's 22 to between 60-100, (WEC 2011), which is an issue that we have to deal with.

Today communicating sustainability is an important topic also for the United Nations Environment Program (UNEP), which are working on producing effective public campaigns in different languages, in order to promote sustainable lifestyle, especially to the countries which are under rush industrial development such as China, Brazil, etc. They recognized the need to communicating sustainability issues in more effective way by dividing their objectives in two stages. During the first phase they developed effective sustainability communicating campaigns, which was meant to serve as a step-bystep guide to building a communication plan. The second phase was on building the capacity of communicators, by organizing training sessions in Brazil and China. Participants in these sessions were national governments, policy specialists, mayors and councilors, marketing experts, NGO`s, consumer associations and academics with an interest in sustainable lifestyle. As it was translated in different languages, platform of communicating sustainability in French and Spanish has been downloaded 700 000 times, a huge number for one publication. There were also another lessons for those who were looking forward to encouraging and engaging people on sustainable lifestyle such as: How to shatter the myths about sustainable way of living, how to develop a communications plan, to identify the obstacles by local and national authorities, to provide best practical examples and identify resources which are necessary to generate change in society.

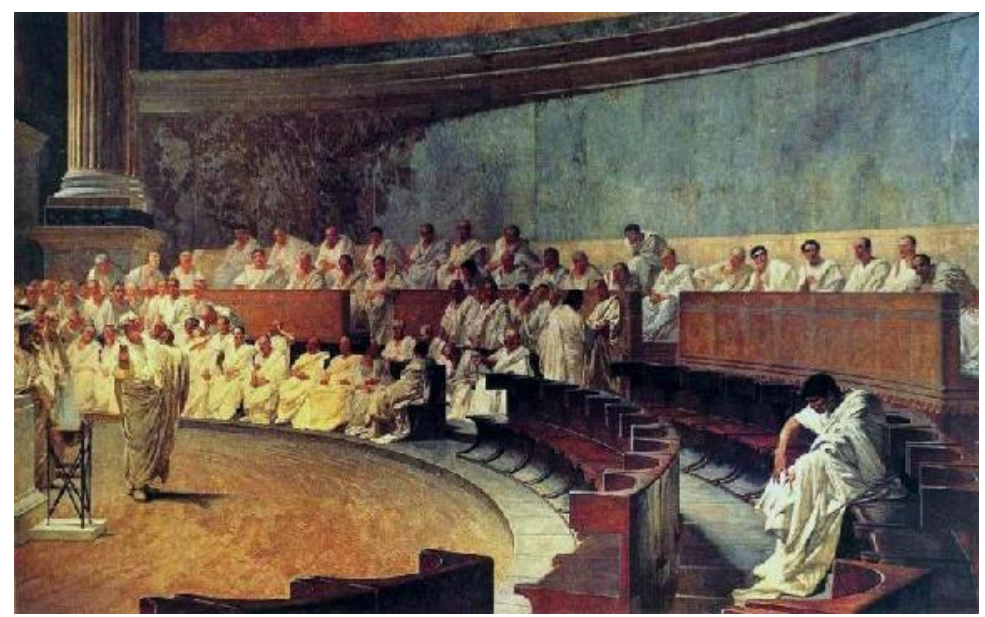

Fig. 5. Public discussion, fresco from Cesare Maccari of 1889, Palazzo Madamma

\subsection{The need for communicating sustainability}

Communicating sustainability could make sustainable way of living reality. The public awareness and concern about environmental, social and economic aspects should be grown more by communication. Today technology has reached the peak of its development and we have to take this advantage to contribute largely in communicating new ways of living, this act would be one of the transparent ways to inform people with reality.

„Sustainability means the relationship between people and their existence/reality. Sustainability could also be arranged on lack of these relations and overcomes. Switzerland as a dense country have little natural resources, which are needed for food production, in order to bring the balance of the city and environment. Switzerland has a demographic problem, less youth people in relation with old ones and 
people in need for care. Basically, it's right that shrinking global population is controlled, so that's why we need new social concepts... "-D.Schwarz.

People should understand their impact which they could have in this world, their only home, and they have to be informed because they are also responsible to take care for it. Public communication has an important role on building with these emerging trends and to make sustainable way of living more approachable and understandable for the people who are building their planet. These sustainable goals that we are developing could be achieved only by the support of committed, motivated and wellinformed people, so this is a matter of communication with people,

however communicating effectively about this topic is a tough challenge. We need to consider not only what we communicate, but how to communicate it.

A communication with public in form of exhibition on moving "The Environmental Train" was organized in Algeria during 2002 - 2003. This exhibition was about raising the awareness of the public about environmental issues and national policy. The „gallery“ in a train carriage was travelling around the country five months by visiting 23 cities and being visited by millions of people. There were two topics in this exhibition: 1 . To communicate environmental issues to the public such as: urban environment, biodiversity, industrial environment and environmental education and 2. To communicate new national policies about environmental issues, which was also introduced in the World Summit on Sustainable Development in Johannesburg, 2002. This way of communication led to the awareness of million people about environmental issues, 35 mayors signed environmental charters and 22 companies have officially committed to establishing an environmental management system for their operations. (UNEP 2005).

\subsection{Problems on communicating sustainability}

It is quite often said that every communication about sustainable living must be good and convincing for the people. But, communications which are badly organized and misplaced will, at least not worked by causing waste of money and waste of time; at worst they could easily have negative consequences. There are three common mistakes which are identified based on the research of UNEP 2005. Communicating without supporting policy. This issue tells that it ${ }^{\text {‘ }}$ always easier to communicate with public in cooperation with national or local policy. If the communicators with public do have the support of certain institutions, they would be more effective on promoting sustainability to the public. „Public education and public policy should be consistent and support each other". (Stevenson, G., 2003). Communicating without infrastructure. Communicating sustainability to the public can be successful in persuading them with new living concepts, but this opportunity will be wasted unless the infrastructure is there to help this communication. For example, there is not possible to motivate people recycle their rubbish if they don't have any easy and convenient access to recycling facilities. Different kind of people have different abilities to support sustainable way of living initiatives. Research shows that in the UK: ,There are particular difficulties for low-income consumers who have fewer household recycling facilities, rely on landlords for housing repairs and, in some areas, have infrequent, unsafe public transport.“ (Stevenson, G., 2003). Relying on mainstream marketing for all answers.,,Getting your message heard is not always easy; the competition is tough.

It is estimated to more than 3000 marketing messages every day. (Public Relation in the Global Economy, 2001). Even if we get our target audience to hear or to see the message, how do we know that they have understand it, absorbed it, remember it and do the people have the ability to change their behavior based on that communication, when in the other side the studies shows that $80 \%$ of the evening TV viewers cannot name a brand or a product advertised in a programmed they have just seen.

\subsection{Objectives of communicating sustainability to the public}

Most communications campaigns have one or more of the following three objectives:

1.Raise awareness: i.e. improves the people's knowledge and make them aware about the issues of living sustainability. What we are really looking forward is public engagement in the process of living sustainable, which means that the main target is the change of their attitude and their behavior.

2.Change attitudes: i.e. presents the way how people think about and feel about an issue. While attitude change could be a precursor to behavior change, it does not guarantee it. Attitude change does, however, 
have an important role to play in preparing for new policy initiatives. It can help to ensure compliance with new legislation, such as for ex. the compulsory of living in houses with 20-30 m2/person.

3.Change behavior: i.e. influence people's actions relating to an issue. This is where efforts should be concentrated if we are to reach our goals on sustainable way of living. However, it‘s a long-term approach, sometimes it takes an entire generation to come to this change.

\subsection{A plan to communicating sustainability to the public}

The best way to successfully start a communication for sustainability, is to created and draw a plan for communicating topics. It's not about creating huge investments to create this plan in national level, but it's also possible to start simply from designing a leaflet for it, which makes possible the communication of some methods and some basic princes of communicating sustainable way of living to the public.

There are some basic notable stages when creating a communication plan about a topic, and those are: Understanding the situation, Audience research, Setting specific objectives, Deciding a strategic approach, Developing the message, Channels and Advertisement, Management and implementation, Measurement and evaluation.

Understanding the situation is an initial research phase that gives us a better chance for success, this section is mainly used for bigger-scale communications with public. This means looking at Social, Environmental, Economic, Political and Technical issues that might affect the communication. National policy is important and also other approaches by other institutions could help to successfully communication with public. By communicating with people, we could also take some important results. Audience research is also an important part for communication, because it helps us to identify and to ensure that our message gets to the right people and they absorb and act on it. So we have to identify the people we want to talk to and priorities them, because there are possibilities that other people could influence other people too, e.g. mothers, fathers, bosses, etc.

Setting specific objectives we make realistic objectives more obvious, e.g. „Cut household energy use by $5 \%$ ", rather than „Mitigate client change“. In this stage we have to decide which of the communicating method is more effective for the public, such as: raise awareness, change attitudes, or change behavior - or all three.

These methods could help on making more precise and more understandable our plans for sustainable way of living for the public.

Deciding on a strategic approach helps the communication to define what we want to achieve with it and which are our objectives. How can we approach a communication, by reviewing the context and objectives, or reviewing alternative approaches or reviewing budget? Communicating these approaches with smaller groups would help on valuable learning from these communications, i.e. communicating sustainability with stakeholders gives them a sense of „ownership“ and means they want to succeed to, so we benefit from their input.

Developing the message could help on addressing the right needs that appeal to the public, and not overload them with too much information. There should be a central thread of message during the communication in order to be more focused. I the economic circumstance allow there could be also a consistent motto for the communication, because it could build an emotional relationship between people we communicate with.

Channels and advertisement will have the impact on communicating the message to the public, but first we have to know in which way the public accept better the message, i.e. internet networks, media, written text or discussions. By being creative with these methods, we can also use social medias to promote our message of sustainability to the people.

Management and implementation makes sure whether our communication with the public could succeed or fail, depending from the way of implementing it. It depends on who is leading this communication, and which are the other team members by defining their roles into the team too. The leader of this communication should be well-known in his sustainable projects which have already proven his theory before communicating it. 
Measurement and evaluation shows the result of planed activities, whether the planned activities were well organized and transmitted to the public and whether the objectives were achieved. Measurement could be based on: 1 . Process - what was communicated to the people, to how many people and how often? 2. Outcomes - which were the changes we made by communication in their awareness, attitude or behavior? 3. Impact - we find which is sustainable way to implement sustainable concepts for public.

\section{Projects about sustainable way of living in City of Bern - CH}

Oops...! The One-Planet Society, Bern $46^{\circ} 57^{`} 3.89^{\prime} \mathrm{N}, 7^{\circ} 26^{`} 19.09^{\prime \prime E}$. There are over 7.4 billion inhabiting our planet, to serve all these people with food, energy and living space according to WWF it is necessary to cultivate 1.5 planets, which is not possible. The work of bringing new sustainable designs have taken place in City of Bern, capital city of Switzerland. There were economical disadvantages in the city because of absorbing many people from the agglomeration to transforming city districts. According to the field of sustainable architecture, these projects are done under the criteria of: identity, social, economic and environmental aspect, technical aspects, constructive ones, and self-sufficiency. These aspects translated into architectural work are treated in different scales, starting from urban scale down to details. Before starting the work, students have visited the city of Bern, in order to get informed from near with old city of Bern, it's identity and districts of the city where the interventions could possibly happen.

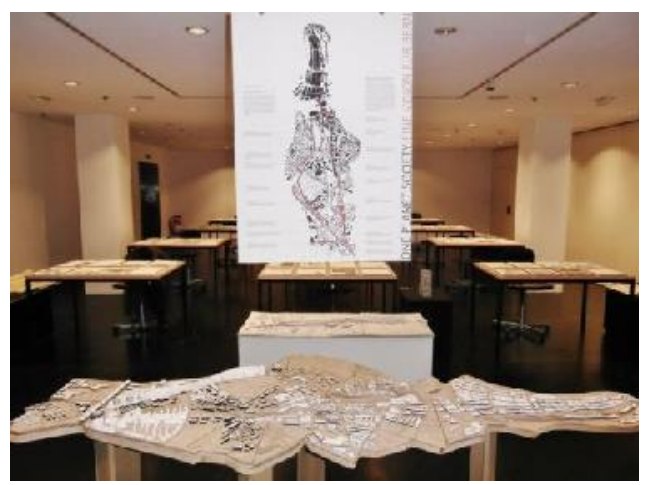

Fig. 6. Situation plans and 3D model of the City Bern. Curator and photography: G.Asani

Student works which are done along the „Track“ and „Crack“, were developed based on sustainable concepts. These sustainable concepts were not only economic, social and environmental ones, but there were many other analysis done in term of using residual spaces of the city, in terms of urban scale they were organizing and connecting districts of the city, sometimes there was mentioned ,creating social bridges" in the city, because connection was considered as a weakness of the city Bern, and that's why we will notice that every project is connecting spaces, areas and districts which still are not connected. A very important aspect of these sustainable designs is density, which means that by organizing and connecting residual spaces of the city, they bring density in the city too. „Factor 4“ was the goal of all these projects for density, which means that we have to bring 4 times more a living area compared with area covered ground floor plan of the building. This aspect raises the growth potential of the city for next years, and still allows a normal development of social life. Sustainable designs which are done for the city of Bern have always been started from calculation of ecological footprint. This helps on identifying the weak point of environmental impact, which later is as a starting point for every design. Higher footprints are mainly closed from: 1. Mobility, 2. Food, and 3. Goods.

Mobility is a matter of transport, nowadays transportation is making a huge environmental impact, and the task comes: how can we reduce mobility with architectural intervention. Food and goods are also important factors for environmental impact, and the task was: how can we make a better organization of a city, in order to save the productive land and use the local food and local resources, in order reduce footprint. 


\subsection{Students strategies for sustainable projects}

Gafur Asani - Densification of residual industrial areas by using surrounding green areas as a potential for bringing biodiversity to new urban settlements, could be a new step forward to build sustainability in a city.

Rodrigo Alba Krasovsky - A way to concentrate people in the city is to take advantage of the areas that are already delimited or confined and that in most cases are forgotten spaces, without identity.

Steffano Schiavon - Humanity as adaptable in our evolution as a specie and it's ability has allowed us to conquer the nature, and now we should bring back the nature as it was.

Natalija Stankovic - Entrances of the city, densification of the unnecessary indrustrial areas and connection between the districts, as a sustainable aspects to bring sustainable projects for the future of a city.

Dimitry Palamarchuk - Densification of the areas which are unused spaces around industrial areas leading to avenue towards the main train station.

Christian Necher - Sustainability by creating new community through integration of the time and space in given site conditions.

Berat Sezer\& Murat Sevgi - The idea of bringing density is about strengthening the front part of the streets with new housing and government offices.

Thomas Moosbrugger - Creating new communities that take advantage of reduced private spaces and common highlights.

Martin Horvat - Integrating all stages of life cycle into the urban life as sustainable development.

Cristina Amman - Densification within the strong existing urban tissue strengthening the front of the boulevard.

Jiahong Li - Connecting insolated industrial areas with infrastructure activating bad areas laying foundation for future densification.

\subsection{Communicating with exhibition}

Exhibition as method of communication form with public, gives the possibility to show and communicate sustainable design works to the public. Architectural exhibition was open a week long for the visitors. The idea of organizing this exhibition was about communicating new sustainable way of living for inhabitants, within their city, but with some interventions made in residual spaces of the city, and also by creating ,social bridges" by connecting different districts of the city Bern with each other. These interventions were represented from up-mentioned student's works, by presenting them in a printed form to the public, and were placed on the tables, which make a better communication between the projects and visitors; they could sit and analyze the projects in order to better understand sustainable projects. A part of this exhibition was the model of the city Bern, followed with other student's models. This way of communications with public, makes more visible and understandable the interventions into the city. During the exhibition was also organized a public presentation about sustainability, which was a good possibility for visitors to better understand the concept of living sustainable.

Advertisement as a part of communicating sustainability was also used for this exhibition, to invite public for this exhibition. This advertisement was made in a written form and electronically ones. For better communicating sustainable way of living we exhibited also researches we did in the studio about living sustainable.

Exhibition remains one of the most important way of communicating sustainability to the public, because instead of exhibiting works, it gives also a possibility to communicate about those works and motivate people to accept sustainability as a life quality.

\subsection{Public presentation about sustainable architecture}

Public presentations have an important role in spreading or communicating the information to the public. In order to successfully transmit a message to the public and change their behavior or make them 
aware about a certain topic, public presentations must be there. The intention of public presentation is not only about informing the public, or communicate a information, but it's goal is also about changing the emotions of listeners, and then make them act or react for that issue. Communicators should be professionals in their professional skills and in their oratorical skills, in order to achieve the goal of communication.

During the architectural exhibition held in city Bern, in order to better communicate sustainable way of living, there were also organized public presentation. This presentation was leaded from, city planner of Bern, Mark WerrenDipl.Arch.ETH/SIA,

from professor of sustainable architecture Dietrich Schwarz Dipl.Arch.ETH/SIA, and from city planner of Bern Jenaette Beck Dipl.Arch.ETH.During these presentations public has the opportunity to hear from the city planners about the problems of city Bern, in term of city growth, culture, identity and left over spaces, and then from the presentation part of sustainable architecture, they had the opportunity to hear about sustainable concepts which are already done.

Professor Dietrich Schwarz presents a further point of view for sustainability, which means a division of our existence/reality in three physical units, mass/energy, space and time. People are transforming endlessly the matter in the space-time continuum. This needs Energy. For architects and planners this means, they have to be efficient with matter and energy, economic with built space, but realized buildings should be more durable / long-lasting as they are today. As a part of this presentation were also student works explained in form of presentation, in order to clarify their sustainable concepts and make more understandable for the visitors. These sustainable concepts are based in terms of social, energy, material, costs and maintenance, identity and environmental impact.

Presentation as a mean of communicating sustainability is also an important part for informing public with new sustainable concepts, because during these presentations there is a possibility to have a direct interaction with public, which makes even stronger the communication with them.

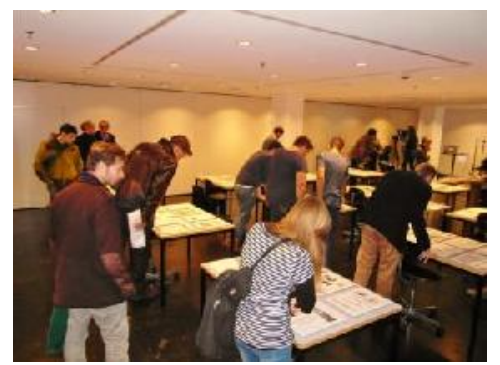

Fig. 7. Visual communication with public. Photography: G.Asani

\subsection{Promotion of sustainability to the public}

In order to better advertise or communicate sustainable way of living to the public, promotion of these concepts is more than necessary. These promotions could create a picture of sustainable way of living in minds of the people, and make them sensible to act for it. In order to be a successful advertisement for sustainability, there are some conditions to be fulfilled such as: presenting the information to the public in a professional way in order to be convincing, to present sustainability as a demand of humanity to save their lives and next generations too, and differentiating sustainability as the only way of living for the future. Elaborating precisely these conditions, would lead to a successful advertisement of sustainable way of living to the public.

Advertisement of sustainable architectural exhibition held in Bern, was also organized in some levels, such as: printed flyers, posters, internet web-pages of Kornhausforum, University of Liechtenstein, social networks, and local newspaper. Advertisements of the sustainable way of living were also happening inside the spaces of the exhibiting area with research books, and semester books. The research book was done from students; there were researched different examples around the world as possible sustainable way of living and semester book as with student works too

Depending on the budget, quality of advertisement has a special importance for communicating a topic to the people. Advertisement remains also one of the most important ways of promoting new sustainable way of living to the public. 


\subsection{Questionnaires and interviews}

In order to measuring and evaluating the exhibition, which was organized as a process of communicating sustainability to the public, there were prepared questionnaires for visitors. There were 36 questionnaires filled from the visitors of this exhibition. These questionnaires were prepared in German Language, in order to be more understandable for the citizens of Bern.

These questionnaires were organized with four questions such as: 1. How did you hear about this exhibition? 2. Which was the best way of presentations to understand the exhibition/topic? 3. Which was the basic idea of sustainable design? 4 . Where do you see the sustainability to the exhibited designs? From question number one we wanted to measure which of the advertisement way were more effective to promote this exhibition, and invite visitors too, and the results show us that social medias together with internet networks have an important role today. With the second question we wanted to see which was the best practical way to understand the communication of sustainable designs, and based on questionnaire, majority said that presentations are very helpful to clarify the concepts, rather than looking only the plans. Answering the third question, majority said that, basic sustainable concepts that they easily understand were sustainability based on mobility, food and goods. Question four identifies the sustainable approaches of the projects based on visitors evaluation, and majority say that, sustainable material, the use of left over spaces and density of the city are important sustainable aspects, that they have seen in the exhibition. In this questionnaire there are also some other additional dates required to be fulfilled from visitors, such as name, surname, age and profession. These data makes possible to see professions of visitors, their ages, and their places where do they come from. From these incomes we could say that visitors were of middle ages, and mainly professionals were visiting it.

Questionnaires as a working method, remains very important in measuring and evaluating a certain topic, in our case it helps on improving weak communication points in order to successfully communicate new sustainable way of living to public.

\section{Discussion of results and Interview}

Discussing results of communicating sustainability to the public convince us that communication with public is a complex work in terms of organizing the whole process. This whole process needs different conditions to be fulfilled in order to be successfully completed. These conditions should be such as: economical ones - whether we have enough budget for a communication process to the public, which also have an impact on the growth of the campaign, professional resources - in terms of having professionals for communication with public and professionals for sustainability, to be more convincing in the minds of public, national and local policy - has also an important place in supporting communications of sustainable way of living to the public, otherwise this process would face different problems and easily could fail. But, there are also practices around the world that communication itself was very important process to bringing changers to the public, in terms of environmental aspects, economic and social aspect. So, for the future communications to the public will still remain key factors to convincing public and bringing changes in society. Organizing exhibition as a way of communicating sustainability to the public was reflected successful, in terms of gathering people and promote them sustainable concepts. This event has special importance for the public, because they had the possibility to see sustainable concepts from near, to "touch“ them, and also hear the presentations about them. Exhibition was also as a meeting point for the people who want the change and are curious for it. In this exhibition people saw but also discussed about these sustainable concepts, actually exhibition created discussions about living sustainable, and this is a step forward to sensibilisating people to act.

\section{Conclusion}

Communicating sustainable way of living to the public/common people will be the topic for the future. The number of megacities in our planet is growing, and the awareness about sustainable way of living 
should be changed in minds of the people. Today we consume more than yesterday, have less productive land than before, because of population growth and the need of ,to build“. This approach is not about changing the size of the planet, but it's about changing people's approach to the resources that offers our planet.

By communicating these resources to the people and demonstrating them with different sustainable designs we come to a point where people understand that living sustainable is possible without affecting their life quality. This communication today is possible more than ever before, by using smart technological devices for communication which helps global coverage within a few seconds.

The need for communicating sustainability has started decades ago when noticed global warming, and now the need for communication is getting even bigger. There are some communications about sustainability in form of summits, agreements, protocols organized in global and national levels, but integrating public/common people in this process is the key. The awareness of common people would have the right effect, because they will help national and global policies in approving the right decisions about sustainability, and this would have a huge impact in reducing global ecological footprint.

In order to successfully communicate sustainability to the public, we have to know and understand first what motivates the public and how should we talk to them. There are some motivating points that we should follow: 1. They want to know what is going on, they hate to be disorientated or confused, 2. They prefer to acquiring information at their own pace and answering their own questions and 3. They want to have a role in this process, they don't participate if they feel incompetent or helpless. These communications need to be inspiring in order to participate in this process. Some important subjects need to be mentioned when communicating sustainability, such as: health, wealth, jobs, environment and life quality.

When making a plan for communicating sustainable way of living to the public, we have to go through some stages which helps this communication and makes it more convincing. We have to understand the place in terms of culture and identity, and the public in terms of ages, professionals, genders, etc. to whom we are communicating to. We have to show the public clear objectives we want to achieve with, whether we want to make them aware, or change their behavior on their way of living, and this part is possible by organizing exhibitions with the sustainable projects done for that place, also discussing with public and public presentations do help the people to really understand from the near concepts of sustainable way of living.

Approaches in communicating with public are important, in order to making them clear the strategies for taking the change initiative. Also promotions of this whole process would lead this communication to a wider public. The leader of this whole communication process should be media-friendly and trustworthy, as well as expert, legitimate figure, in order to be convincing with their speeches. Teamwork in organizing this whole process and clearly defining competences for team members are necessary.

Today, environmental changes over the globe surprises us very often with different unpredictable reactions, such as, raise of temperatures, higher water levels, etc., also human made reactions, such as, wars for natural resources tells us that we have to reduce our demands, in order to have the stability in our planet, and communicating sustainability to the people would clearly have the right impact to it.

\section{References}

1 Collins, J., Thomas, G., Willis, R. and Wilsdon, J. (2003). Carrots, Sticks and Sermons: Influencing public behavior for environmental goals. London: Demos/Green Alliance.

2 Kaplan, S. (2000), Human Nature and Environmentally Responsible Behavior. Journal of Social Issues. Malden, MA: Blackwell Publishers.

3 MORI / International Environment Monitor (1998).

4 MPG International (December 2004), Sustainable motivation, Attitudinal and behavioral drivers for action, report on UNEP Sustainable Motivation project sponsored by the World Association of Research Professionals (ESOMAR), http://www.mpgintl.com/sustain 
5 McKenzie-Mohr, D. (2000). Promoting Sustainable Behavior: An Introduction to CommunityBased Social Marketing, Journal of Social Issues. London: Blackwell.

6 Stevenson, G., ed. (2003), Green Choice: What choice? London: National Consumer Council.

7 Bruntland, G, ed., (1987). Our common future: The World Commission on Environment and Development. Oxford: Oxford University Press.

8 UN Global Compact, (2005). What is the Global Compact? http://www.unglobalcompact.org/Portal/Default.asp

9 Aguilera, Jose Miguel and David W. Stanley. Micro structural Principles of Food Processing and Engineering. Springer, 1999.

10 Humphery, Kim. Shelf Life: Supermarkets and the Changing Cultures of Consumption. Cambridge University Press, 1998 